\title{
Prolonged Extracorporeal Membrane Oxygenation Support In a Patient with Drug Reaction with Eosinophilia and Systemic Symptoms Syndrome-associated Fulminant Myocarditis - A Case Report and Literature Review
}

\author{
Chutima Seree-aphinan, Nawaporn Assanangkornchai and Thanapon Nilmoje \\ Department of Internal Medicine, Faculty of Medicine, Prince of Songkla University, Songkhla, Thailand
}

DOI: https://doi.org/10.17925/HI.2020.14.2.112

\begin{abstract}
ntroduction: Myocarditis is a rare presentation of drug reaction with eosinophilia and systemic symptoms (DRESS) syndrome, traditionally associated with poor clinical outcomes. Prompt recognition and treatment are crucial. Case presentation: A 16-year-old patient presented with acute chest pain, hypotension, and pulmonary oedema 2 months after being diagnosed with trimethoprim/sulfamethoxazole-induced DRESS syndrome. Typical DRESS features were absent at onset of these symptoms. Echocardiography demonstrated biventricular systolic dysfunction, and electrocardiography (ECG) showed complete right bundle branch block and diffuse ST-segment elevation. The patient was admitted for high-dose inotropic support; however, his condition deteriorated. Veno-arterial extracorporeal membrane oxygenation (VA-ECMO) and intra-aortic balloon pump were initiated on the third day of admission. Endomyocardial biopsy suggested the diagnosis of DRESS-associated myocarditis and a high-dose corticosteroid was commenced. While he was ECMO-dependent, the patient suffered multiple episodes of ventricular tachycardia on a background of cardioversion-resistant accelerated idioventricular rhythm. After 24 days of ECMO support, the ventricular function improved, and ECG reverted to sinus rhythm. His recovery allowed corticosteroid discontinuation 15 months after hospital discharge. Conclusion: Typical DRESS syndrome features may not accompany the onset of DRESS-associated myocarditis. Mechanical circulatory support and adequate immunosuppression could save patients with malignant arrhythmias and delayed myocardial recovery.
\end{abstract}

\section{Keywords}

Drug reaction with eosinophilia and systemic symptoms (DRESS), drug-induced hypersensitivity syndrome, myocarditis, extracorporeal membrane oxygenation (ECMO)

Disclosures: Chutima Seree-aphinan, Nawaporn Assanangkornchai and Thanapon Nilmoje have no financial or non-financial relationships or activities to declare in relation to this article. Review Process: Double-blind peer review. Compliance with Ethics: Informed consent was received from the patient and his legal guardian. Authorship: The named authors meet the International Committee of Medical Journal Editors (ICMJE) criteria for authorship of this manuscript, take responsibility for the integrity of the work as a whole, and have given final approval for the version to be published.

Access: This article is freely accessible at touchCARDIO.com (C) Touch Medical Media 2020

Submitted: 11 August 2020

Accepted: 9 November 2020

Published online: 11 December 2020

Citation: Heart International. 2020;14(2):112-7

Corresponding Author: Thanapon Nilmoje, Division of Cardiology, Department of Internal Medicine,

Faculty of Medicine, Prince of Songkla University,

15 Kanjanavanit road, Hatyai, Songkhla, 90110, Thailand. E: thanapon.n@psu.ac.th

Support: No funding was received in

the publication of this article.
Drug reaction with eosinophilia and systemic symptoms (DRESS) syndrome is a severe cutaneous adverse drug reaction. Symptoms comprise fever, Iymphadenopathy, rash, and eosinophilia, with or without visceral organ involvement. The extent of internal organ involvement, including hepatitis, myocarditis, pneumonitis, thyroiditis and pancreatitis, determines the morbidity and mortality associated with the disease. ${ }^{1-3}$ We report a case of DRESS-associated myocarditis in a patient who survived after a prolonged period of veno-arterial extracorporeal membrane oxygenation (VA-ECMO) support. Recognition of this condition is crucial because it is rare and severe. With the availability of an advanced mechanical circulatory support system, patient outcomes could be improved.

\section{Case presentation}

A healthy, 16-year-old male presented with acute fever and generalised maculopapular rash, 3 months after he started taking trimethoprim/sulfamethoxazole for the treatment of acne. The rash progressed to generalised erythroderma in 4 days. His vital signs and oxygen saturation were normal, except for a body temperature of $39.5^{\circ} \mathrm{C}$. He also had cervical lymphadenopathy and hepatomegaly. Chest pain or discomfort, dyspnoea, and peripheral oedema were absent. His full blood count showed eosinophilia (absolute eosinophil count 1,618 cells/ $\mu \mathrm{L}$ ) and the presence of atypical lymphocytes. Liver enzymes and bilirubin level were elevated (total bilirubin $7.25 \mathrm{mg} / \mathrm{dL}$, direct bilirubin $6.86 \mathrm{mg} / \mathrm{dL}$, aspartate aminotransferase $274 \mathrm{U} / \mathrm{L}$, alanine aminotransferase $501 \mathrm{U} / \mathrm{L}$, alkaline phosphatase $340 \mathrm{U} / \mathrm{L}$, albumin $3.4 \mathrm{~g} / \mathrm{L}$, total protein $5.4 \mathrm{~g} / \mathrm{L}$ ). Serum creatinine level and urinalysis were normal. No cardiomegaly or pulmonary infiltrate was seen on chest X-ray. The patient was diagnosed with definite DRESS syndrome with a Registry of Severe Cutaneous Adverse Reaction (RegiSCAR) DRESS score of $6 .{ }^{4}$ Trimethoprim/sulfamethoxazole was discontinued, and $60 \mathrm{mg} /$ day of oral prednisolone ( $1 \mathrm{mg} / \mathrm{kg} / \mathrm{day}$ ) was prescribed. With clinical improvement, the prednisolone dose was gradually decreased, reaching $30 \mathrm{mg} /$ day at the end of the first month. In the second month, prednisolone was tapered by $10 \mathrm{mg}$ every 2 weeks. During this period, fever and rash did not 
Figure 1: Chronological changes observed with chest X-ray and electrocardiogram from disease onset to clinical resolution

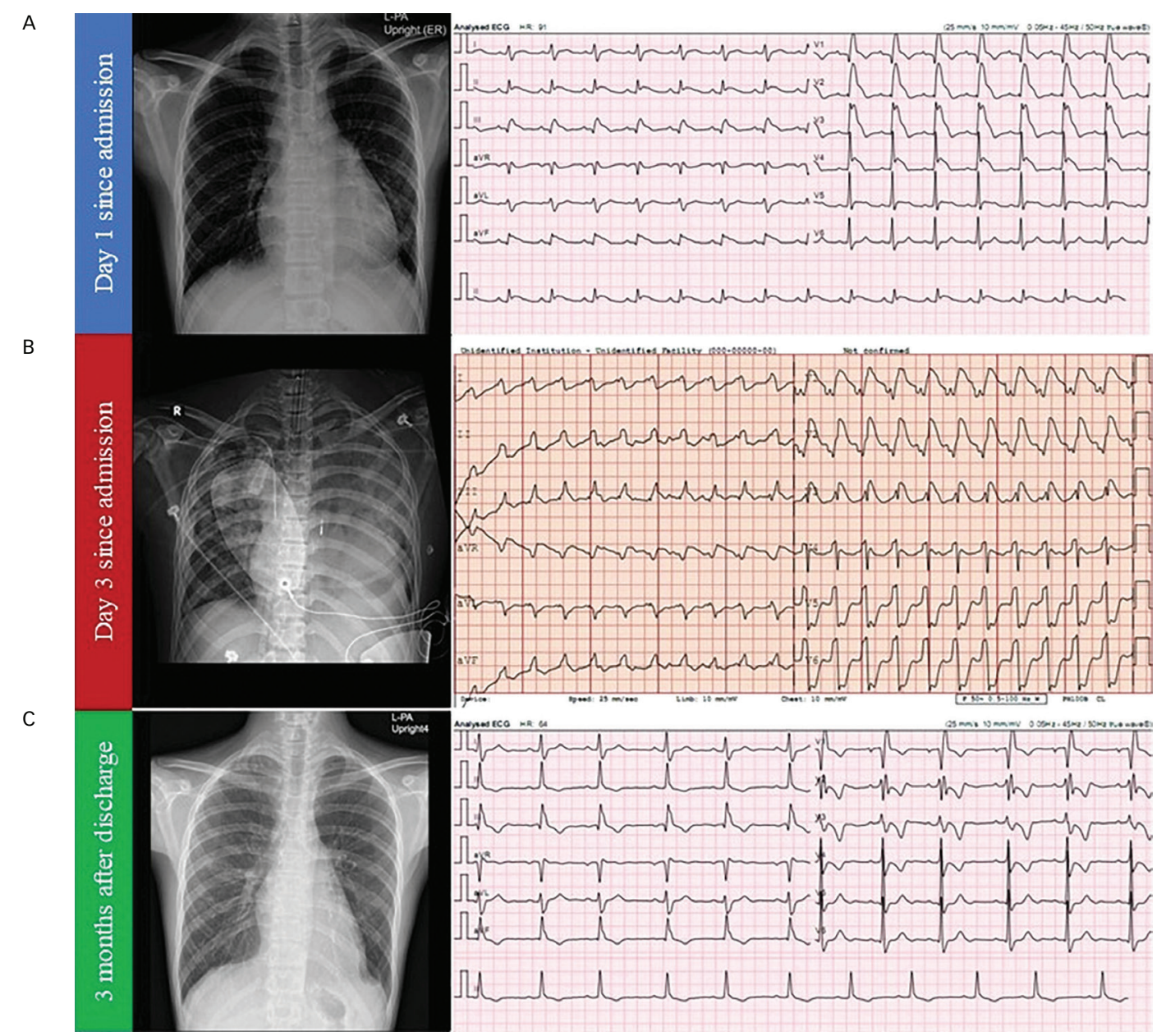

On presentation, the patient's chest X-ray demonstrated mild cardiomegaly, while his echocardiogram showed sinus tachycardia with complete right bundle branch block and diffuse ST-segment elevation (A). Within 3 days after admission, his heart size rapidly enlarged, which is associated with pulmonary oedema, and his heart rhythm became an accelerated idioventricular rhythm (B). After successful treatment, heart size and rhythm normalised 3 months after discharge, despite residual right bundle branch block (C).

recur. Lymphadenopathy and hepatomegaly were resolved. The patient's liver function gradually improved; values at the end of the second month were as follows: total bilirubin $1.28 \mathrm{mg} / \mathrm{dL}$, direct bilirubin $1.06 \mathrm{mg} / \mathrm{dL}$, aspartate aminotransferase $114 \mathrm{U} / \mathrm{L}$, alanine aminotransferase $291 \mathrm{U} / \mathrm{L}$, alkaline phosphatase $164 \mathrm{U} / \mathrm{L}$.

Two months after treatment, as prednisolone was tapered to $10 \mathrm{mg} /$ day, the patient presented to the emergency department with a 2-day history of substernal chest pain and dyspnoea. On examination, he was alert and cooperative. His body temperature was $37.8^{\circ} \mathrm{C}$, his blood pressure was $88 / 48 \mathrm{mmHg}$, his pulse rate was 110 beats per minute (bpm), his respiratory rate was 22 breaths per minute, and his oxygen saturation was $98 \%$ on room air. His extremities were non-oedematous but cold, with slow capillary refill and weak pulses. His heart sound was regular without abnormal sound, and his chest examination was unremarkable. There was no rash, lymphadenopathy, nor hepatomegaly. Chest X-ray demonstrated diffuse cardiomegaly with perihilar patchy infiltration. Electrocardiography (ECG) showed sinus tachycardia with complete right bundle branch block and diffuse ST-segment elevation (Figure 1A). High-sensitivity C-reactive protein level was elevated (31.65 mg/L; normal range: $<5 \mathrm{mg} / \mathrm{L}$ ) but erythrocyte sedimentation rate was normal $(1 \mathrm{~mm} / \mathrm{hr}$; normal range: 0-15 mm/hr). Troponin-T level was 7,190 ng/L (normal range: $<14$ ng/L), N-terminal pro B-type natriuretic peptide (NT-proBNP) level was
$14,337 \mathrm{pg} / \mathrm{mL}$ (normal range: $<125 \mathrm{pg} / \mathrm{mL}$ ), and arterial lactate level was $2.1 \mathrm{mmol} / \mathrm{L}$. There was no eosinophilia on this presentation (absolute eosinophil count $224 \mathrm{cell} / \mathrm{s} / \mathrm{L}$ ). Echocardiography found a $1.4 \mathrm{~cm}$ pericardial effusion without echocardiographic cardiac tamponade physiology; globally severe left ventricular systolic dysfunction with the left ventricular ejection fraction (LVEF) of $25 \%$ by modified Simpson's biplane; and thickening of the interventricular septum and the right ventricular wall. The patient was diagnosed with myopericarditis with congestive heart failure and cardiogenic shock. Given the prior diagnosis of DRESS syndrome, DRESS-related myocarditis could not be excluded. Intravenous hydrocortisone at the dose of $200 \mathrm{mg} /$ day was promptly administered while waiting for further investigations. He was then transferred to a cardiac care unit for close observation.

Despite high-dose inotropes, vasopressors, and diuretics, the patient continued to deteriorate with increased tachycardia, hypotension, acute renal failure, increased liver enzymes and rising of arterial lactate to $14.8 \mathrm{mmol} / \mathrm{L}$. On the third day of admission, the decision was made to initiate VA-ECMO via bi-femoral approach for total circulatory support and an intra-aortic balloon pump (IABP) for left ventricular systolic unloading. Repeat echocardiography found that the left ventricle was dilated with global thinning of the left ventricular wall and LVEF of $14 \%$ by modified Simpson's biplane. His ECG changed to continuous wide 


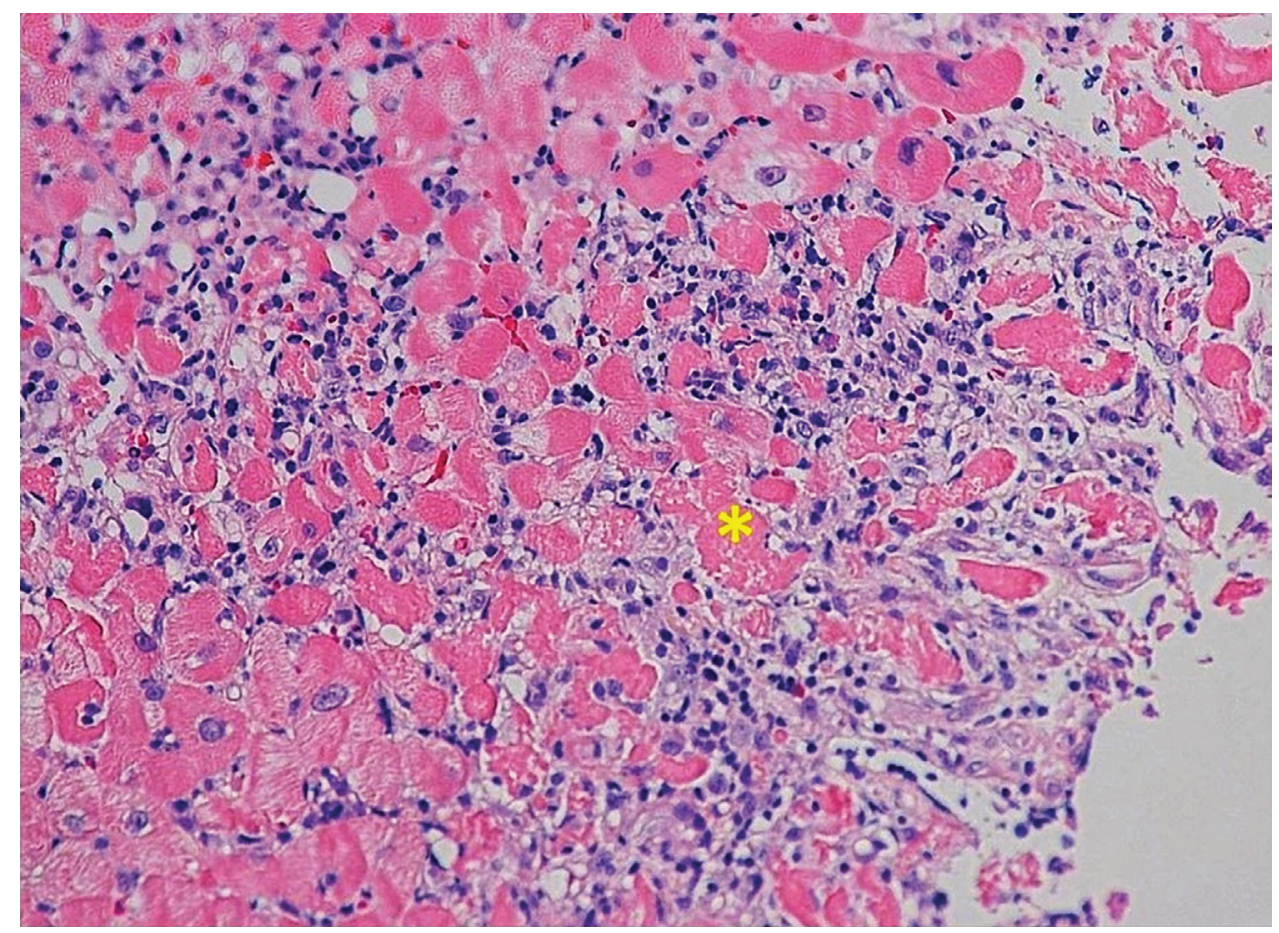

Haematoxylin-eosin stained endomyocardial tissue, viewed at 40x magnification, showing a mixed inflammatory infiltrate composed of many T-cells (CD3+, CD8+, CD56-, EBER-), $B$-cells, histiocytes and a few eosinophils. Small foci of muscle necrosis (yellow asterisk) and some areas of fibrosis were also found.

complex tachycardia with a ventricular rate of 88-120 bpm and episodic heart rate elevation to 130-150 bpm: these findings were consistent with accelerated idioventricular rhythm and intermittent short-run ventricular tachycardia (Figure 1B). Trials of electrical cardioversion and medical cardioversion with amiodarone and lidocaine failed to revert his ECG to sinus rhythm.

Blood cultures and serology tests for Epstein-Barr virus; cytomegalovirus; human herpes viruses 1-6; adenovirus; enterovirus; coxsackie viruses; rubella virus; hepatitis viruses $\mathrm{A}, \mathrm{B}$ and $\mathrm{C}$; chikungunya virus; rickettsial infections; mycoplasma infection; and antinuclear antibody were negative. A transjugular endomyocardial biopsy, performed on the sixth day of admission, revealed mixed inflammatory infiltrate composed of numerous lymphocytes and histiocytes as well as few scattered eosinophils. Lymphocytes were mostly $\mathrm{T}$ cells (CD3+, CD4+, CD8+, CD56-, EBER-). Very few B cells were found. Small foci of muscle necrosis and some areas of fibrosis were also identified (Figure 2). The patient's prior diagnosis of DRESS syndrome and pathology findings, alongside negative infectious and autoimmune tests, was suggestive of DRESS-associated myocarditis.

On day 8 following his admission, the patient was stabilised on full VA-ECMO support. Norepinephrine and dobutamine were completely withdrawn, while milrinone was intentionally fixed at a low dose. Shock-related liver and kidney injuries recovered. However, arrhythmias persisted: he was still persistently in accelerated idioventricular rhythm with intermittent episodes of ventricular tachycardia. In addition, the left ventricle remained dilated with poor left ventricular systolic function (LVEF $16 \%$ by modified Simpson's biplane). Levosimendan was given to augment myocardial contractility using a standard dosing regimen for acute decompensated heart failure.
On the third week of admission, spontaneous conversion to sinus rhythm with progressive narrowing of QRS complex occurred. VA-ECMO support was weaned off and decannulated on the 24th day of the run. IABP was removed the next day, and the patient was extubated 6 days later. Follow-up echocardiography after VA-ECMO decannulation found gradually improved LVEF. No serious complications developed during the VA-ECMO run. Intravenous hydrocortisone at $200 \mathrm{mg}$ /day was switched to oral prednisolone at $1 \mathrm{mg} / \mathrm{kg} /$ day after an oral diet was resumed. A beta-blocker, angiotensin-converting enzyme inhibitor, digoxin, and spironolactone were started before the patient was discharged, to improve systolic function. The total duration of hospitalisation was 6 weeks.

Chest X-ray and ECG performed 3 months after discharge showed reduced cardiac size with residual right bundle branch block (Figure 1C). At his 9-month follow-up, the patient remained asymptomatic, although mild left ventricular dysfunction persisted (LVEF $44 \%$ by modified Simpson's biplane). Guided by symptoms and cardiac enzymes, prednisolone was tapered off over 15 months. To date, there have been no signs of DRESS relapse during outpatient visits, and the patient has reported that he is currently functioning at pre-hospital baseline levels.

\section{Discussion}

By searching the PubMed database using the keywords 'DRESS' or 'drug-induced hypersensitivity syndrome' and 'myocarditis', as of August 2020, we identified 63 reported cases of DRESS-associated myocarditis in the literature: 43 case reports, ${ }^{5-47}$ four case series, ${ }^{48-51}$ and three small observational studies. ${ }^{52-54}$ The incidence of DRESS-associated myocarditis ranged from one to five cases per year (Figure 3). However, the true incidence of this disease is yet to be established, as cardiac evaluation in patients with DRESS is not routinely performed in clinical practice, and no results from large or 
Figure 3: The number of reported cases of DRESS-associated myocarditis by year

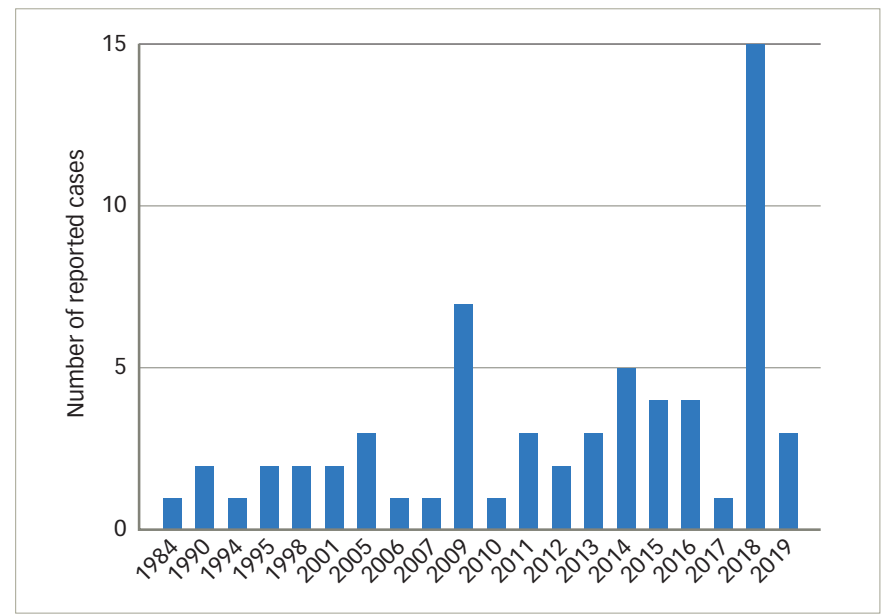

Each column represents the number of published cases identified through our literature review, sorted by year of publication.

population-based studies focusing specifically on DRESS-associated myocarditis are currently available.

A review of the literature revealed 38 drugs associated with DRESS-associated myocarditis (Table 1). ${ }^{5-54}$ Only 2 reported cases were associated with trimethoprim/sulfamethoxazole.

Myocarditis may complicate the clinical course of DRESS syndrome, either at the time of diagnosis or later in the disease course. Fifty-nine per cent of DRESS-associated myocarditis cases identified in the literature review occurred concurrently with the first diagnosis of DRESS syndrome, while the remaining cases presented later during treatment. The period from the first DRESS symptoms to symptomatic onset of the first myocarditis episode varied from 1 week to 6 months. Moreover, among the identified cases in which symptoms of myocarditis arose late in the clinical course, $42 \%$ did not have any features suggestive of DRESS syndrome (i.e. fever, rash, lymphadenopathy, eosinophilia). Also, in patients who had DRESS relapses after the onset of myocarditis, cardiac involvement did not accompany every subsequent relapse episode. ${ }^{35,36,51}$ Hence, a high index of clinical suspicion is paramount for detecting myocarditis in patients with DRESS syndrome.

According to the identified cases, patients with DRESS-associated myocarditis often presented with chest or epigastric pain, chest discomfort, dyspnoea with or without exertion, and syncope, which progressed in an acute or subacute manner. At the extreme, they could be brought to hospitals in cardiogenic shock $5,8,7,7,18,25,33,3,4,42,4,4,4,55$ or cardiac arrest. ${ }^{15,20}$ Asymptomatic patients were also identified. ${ }^{52}$ Regarding cardiac abnormalities, myocarditis of DRESS syndrome manifests with a combination of electrical abnormalities and myocardial injuries. However, five cases reported isolated electrical abnormalities ${ }^{23,52,53}$ and 15 cases reported isolated myocardial injuries. ${ }^{10,13,19,31,33-35,51,52}$ Overall, the most common arrhythmias were sinus tachycardia and right bundle branch block (Table 2), ${ }^{5-9,11,12,14,16-18,21-23,25-30,32,37-41,43-53}$ usually appearing as initial rhythms on admission. On the contrary, ventricular arrhythmias and complete heart block mostly happened late in the clinical course. Interestingly, 73\% of the identified case report patients with ST-segment elevation had a regional distribution mimicking an ischaemic pattern (Table 2: ST segment changes). In the patients with myocardial injuries, severity varied from asymptomatic troponitis to fulminant
Table 1: Culprit drugs associated with DRESS-associated myocarditis*

\begin{tabular}{|c|c|}
\hline Antibiotics & 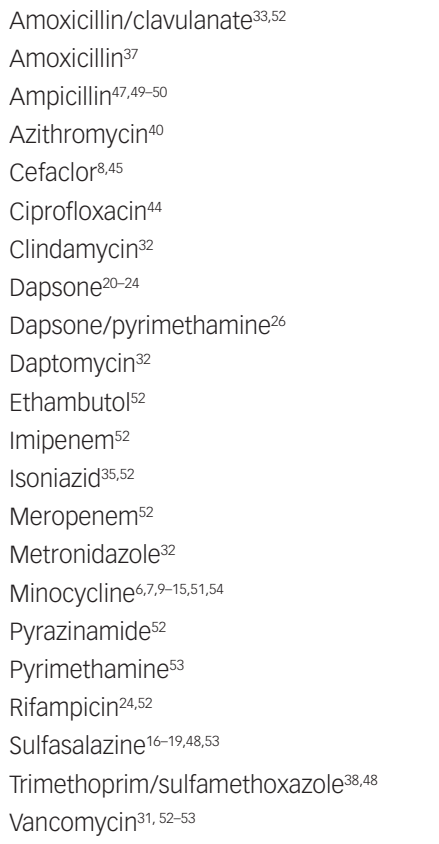 \\
\hline Antiepileptics & $\begin{array}{l}\text { Carbamazepine }^{5,28} \\
\text { Lamotrigine }^{29,51} \\
\text { Phenobarbital } 36,46,49 \\
\text { Phenytoin } \\
5,43,52\end{array}$ \\
\hline $\begin{array}{l}\text { Antipsychotics and } \\
\text { antidepressants }\end{array}$ & $\begin{array}{l}\text { Amitriptyline }^{25,39} \\
\text { Benztropine }^{27} \\
\text { Clonazepam }^{5} \\
\text { Fluphenazine }^{27} \\
\text { Lithium²,30 }^{27} \\
\text { Quetiapine }^{30}\end{array}$ \\
\hline Others & $\begin{array}{l}\text { Allopurinol}{ }^{34} \\
\text { Colchicine }^{34} \\
\text { Hydroxyurea }^{53} \\
\text { Mexiletine }^{42} \\
\text { Modafinil }^{41} \\
\text { Non-steroidal anti-inflammatory drugs }^{8,39} \\
\text { Zosinamide }^{48}\end{array}$ \\
\hline
\end{tabular}

*In some cases, ${ }^{2,5,8,24,27,30,32,34,39,48,49}$ a single culprit drug could not be identified due to simultaneous initiation of multiple drugs.

myocarditis. Echocardiographic data were available in 52 of the identified cases; global hypokinesia and pericardial effusion were reported in $75 \%$ and $38 \%$ of them, respectively. Other abnormal findings included left ventricular dysfunction with regional wall motion abnormalities, ${ }^{11,37,41,53}$ ventricular wall thickening, $8,39,41,4,46$ and reduced fractional shortening with preserved left ventricular ejection fraction..$^{10}$

Of all reported cases we found in the literature review, myocardial tissue biopsy was performed in 29 cases (46\%). Thirteen cases were post-mortem studies, $711,15,17-20,24,3,4,41,48-50$ while the rest of the cases obtained myocardial tissue via transjugular endomyocardial biopsy $9,13,14,16,2,2,29,30,35,37,40,44-46$ or open biopsy. ${ }^{12,48}$ Except for a few early cases, ${ }^{49,50}$ almost all patients in the reported cases of DRESS-associated myocarditis underwent biopsies after initiation of a corticosteroid. The pathological finding from most cases revealed diffuse interstitial infiltration of mixed inflammatory cells, including eosinophils, lymphocytes, histiocytes, and plasma cells. The proportion of eosinophils 
Table 2: Electrocardiographic abnormalities reported in DRESS-associated myocarditis

\begin{tabular}{|c|c|c|}
\hline \multicolumn{2}{|c|}{ Electrocardiographic abnormalities } & $\begin{array}{l}\text { Number of } \\
\text { cases reported }\end{array}$ \\
\hline \multirow[t]{2}{*}{ Sinus arrhythmias } & Sinus tachycardia ${ }^{11,14,17,21,25,27-29,39-41,45,47,50,52}$ & 16 \\
\hline & Sinus bradycardia ${ }^{30}$ & 1 \\
\hline \multirow{3}{*}{$\begin{array}{l}\text { Supraventricular } \\
\text { tachyarrhythmias }\end{array}$} & Paroxysmal atrial contraction ${ }^{23}$ & 1 \\
\hline & Atrial tachycardia $^{16}$ & 1 \\
\hline & $\begin{array}{l}\text { Supraventricular tachycardia } \\
\text { (unspecified origin) })^{21,52}\end{array}$ & 2 \\
\hline \multirow[t]{4}{*}{ Conduction block } & $\begin{array}{l}\text { Right bundle branch } \\
\text { block }^{6,7,9,12,18,26,40,47,50,51}\end{array}$ & 10 \\
\hline & Atrioventricular block $* 5,6,11,23,29,46,52$ & 7 \\
\hline & Left anterior fascicular block ${ }^{23}$ & 1 \\
\hline & Left bundle branch block ${ }^{11}$ & 1 \\
\hline $\begin{array}{l}\text { QRS complex } \\
\text { abnormalities }\end{array}$ & Pathologic Q waves at V1-V2 29,49 & 3 \\
\hline \multirow{6}{*}{$\begin{array}{l}\text { ST segment } \\
\text { changes }\end{array}$} & ST elevation: anterior wall ${ }^{5,14,18,22,46,52}$ & 6 \\
\hline & ST elevation: lateral wall $18,37,41$ & 3 \\
\hline & ST elevation: inferior wall ${ }^{37,48}$ & 2 \\
\hline & ST elevation: posterior wall & 0 \\
\hline & ST elevation: widespread $9,21,44,48$ & 4 \\
\hline & ST depression ${ }^{49,53}$ & 2 \\
\hline \multirow{6}{*}{$\begin{array}{l}\text { Ventricular } \\
\text { arrhythmia }\end{array}$} & T waves inversion $8,43,52,53$ & 7 \\
\hline & Biphasic T waves ${ }^{47}$ & 1 \\
\hline & Non-specific ST-T changes $23,29,39,41,49,51$ & 6 \\
\hline & Accelerated idioventricular rhythm ${ }^{5,11,16,41}$ & 4 \\
\hline & $\begin{array}{l}\text { Ventricular tachycardia or ventricular } \\
\text { fibrillation } 11,12,18,21,38,41\end{array}$ & 6 \\
\hline & $\begin{array}{l}\text { Paroxysmal ventricular } \\
\text { contraction } 17,32,47,49\end{array}$ & 4 \\
\hline \multirow[t]{2}{*}{ Others } & Asystole $^{49}$ & 1 \\
\hline & Pulseless electrical activity ${ }^{7}$ & 1 \\
\hline
\end{tabular}

*Arioventricular block varied from first degree to complete atrioventricular block.

differed between cases. Among non-survivors, the amount of eosinophil infiltration also varied and was not always predominant. Three cases

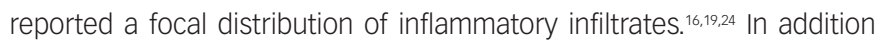
to the inflammation, scattered multinucleated giant cells, $S^{9,1,14,20,29,48,49}$ and interstitial fibrosis $s^{9,2,30,35,46}$ were the most frequently reported associated findings. Microabscesses, ${ }^{50}$ haemorrhage, ${ }^{18}$ interstitial oedema9,45 and eosinophilic thrombus ${ }^{34}$ were also found.

In the absence of tissue pathology, the diagnosis of DRESS-associated myocarditis is based on the compatible clinical setting (i.e. fulfil the diagnosis of DRESS syndrome by RegiSCAR criteria on admission or previously diagnosed with DRESS syndrome), ${ }^{4}$ exclusion of possible infectious and autoimmune causes, and one of the following investigations: imaging (echocardiogram or cardiac magnetic resonance imaging), cardiac enzymes and ECG. Pericardial effusion on chest computerised tomography scan is also an incidental finding suggestive of DRESS-related myocarditis. ${ }^{6,35}$ In cases in which the patient's presentation was similar to that of an acute coronary syndrome, it was excluded either by coronary angiogram or clinically, by having a low coronary risk profile.
Immunosuppression has been considered a primary treatment of DRESS-associated myocarditis, with supporting evidence from observational and anecdotal data. ${ }^{1}$ Among the identified DRESS-associated myocarditis cases, systemic corticosteroids are the mainstay of the regimen, which has been given as pulse therapy and in high dose, with slow tapering over one month or longer, up to one year. Intravenous immunoglobulin, $0^{67,10,12,16,23,27,3,4,45,48,51}$ plasmapheresis ${ }^{5,13}$ and anti-thymocyte globulin7.9 were used as additional treatment during acute episodes. Azathioprine, ${ }^{40,44}$ cyclosporine, ${ }^{7,1029,51}$ mepolizumab, ${ }^{29}$ methotrexate, $^{51}$ mycophenolate mofetil, 7, 19,2,29,30,48 and tofacitinib ${ }^{51}$ were alternative immunosuppressive agents used in the reported cases. No complications from these medications were reported, except for one case of intra-abdominal sepsis, which developed during azathioprine treatment. ${ }^{40}$ There is a scarcity of evidence to assess the efficacy of these steroid-sparing medications; their selection is dependent upon expert opinion.

Despite immunosuppressive therapies, 33 patients (52\%) suffered a fulminant disease course, resulting in an overall mortality rate of $44 \%$ among the identified cases of DRESS-associated myocarditis. Severe ventricular dysfunction and refractory ventricular arrhythmia were the main conditions leading to death. Physicians were able to establish mechanical circulatory support in 14 patients as a bridge to recovery or transplantation. Nine patients received IABP, $5,6,9,3,38,41,4,4,4,51,8$ patients received VA-ECMO support, $, 5-8,2,16,2,2,382$ patients received ventricular assisted device implantation ${ }^{12,48}$ and 1 patient underwent a cardiac transplant; ${ }^{41}$ only 7 of them survived..$^{5-8,48}$ Our patient is the eighth survivor with the longest duration of ECMO support at 24 days. Our case suggests that, with more time permitted, cardiac function may eventually recover in some patients who would not otherwise survive. We believe that, with further advancement of circulatory support medications and devices for severe cardiac failure, patient outcomes could improve.

Our case report gives new insight into DRESS-associated myocarditis and emphasises several aspects of its natural history. Firstly, as we successfully provided prolonged ECMO support without complications, our patient's survival enables us to provide data on the longitudinal evolution of ECG abnormalities in patients with DRESS-associated myocarditis and malignant ventricular arrhythmias who predominantly succumb to early death, as highlighted in previously published case reports. This information could help guide physicians on a possible timescale of expected recovery of fulminant DRESS-associated myocarditis following treatment, especially in the presence of malignant arrhythmia, in which neither a ventricular assisted device nor cardiac transplantation is helpful. Secondly, our case underlines that myocarditis can bethesole presentation of DRESS relapse; it is not necessary to have other typical DRESS symptoms present at the diagnosis of DRESS-associated myocarditis. We believe prompt recognition of this aspect of the natural history of DRESS-associated myocarditis by our team allowed us to establish treatment in the right direction without delay. Lastly, the tissue inflammatory responses observed in DRESS-associated myocarditis are not limited to an eosinophilic-rich reaction. In fact, tissue pathology from many non-survivors showed mixed inflammatory responses rather than an eosinophil-predominant reaction. Therefore, the diagnosis of DRESS-associated myocarditis relies heavily on a firm diagnosis of DRESS syndrome, demonstration of myocarditis and exclusion of infectious and autoimmune causes. One limitation of our approach to this patient is that we were unable to transfer the patient for cardiac magnetic resonance imaging during admission and therefore we cannot comprehensively illustrate the topographic area of cardiac pathology in this patient. 


\section{Conclusion}

To summarise, we report a rare case of myocarditis, which occurred as a late-onset complication of DRESS syndrome. DRESS-associated myocarditis may complicate DRESS syndrome either at the time of the diagnosis or later in the disease course. In the latter situation, as demonstrated by our patient's presentation, typical DRESS features (e.g. fever, rash, lymphadenopathy) may not accompany the onset of myocarditis. ECG could provide clues for diagnosis and mark the recovery point. This case highlights the potential importance of mechanical circulatory support, along with adequate immunosuppression, in saving patients with malignant ventricular arrhythmias and delayed myocardial recovery.
1. Duong $T A$, Valeyrie-Allanore $L$, Wolkenstein $P$, et al Severe cutaneous adverse reactions to drugs. Lancet. 2017;390:1996-2011.

2. Taweesedt PT, Nordstrom CW, Stoeckel J, et al. Pulmonary manifestations of drug reaction with eosinophilia and systemic symptoms (DRESS) syndrome: A systematic review. Biomed Res Int. 2019:2019:7863815.

3. Husain Z, Reddy BY, SchwartZ RA. DRESS syndrome: Part I. Clinical perspectives. J Am Acad Dermatol. 2013;68:693.e1-14; quiz 706-8.

4. Kardaun SH, Sekula P, Valeyrie-Allanore L, et al. Drug reaction with eosinophilia and systemic symptoms (DRESS): an original multisystem adverse drug reaction. Results from the prospective RegiSCAR study. Br J Dermatol. 2013;169:1071-80.

5. Lo M-H, Huang C-F, Chang L-S, et al. Drug reaction with eosinophilia and systemic symptoms syndrome associated myocarditis: a survival experience after extracorporeal membrane oxygenation support. I Clin Pharm Ther. 2013;38:172-4.

6. Kanno K, Sakai H, Yamada Y, et al. Drug-induced hypersensitivity syndrome due to minocycline complicated by severe myocarditis. J Dermatol. 2014:41:160-2.

7. Howell E, Paivanas N, Stern J, et al. Treatment of acute necrotizing eosinophilic myocarditis with immunosuppression and mechanical circulatory support. Circ Heart Fail. 2016:9:e003665.

8. Morikawa D. Hiraoka E Obunai $K$ et al. Myocarditis associated with drug reaction with eosinophilia and systemic symptoms (DRESS) syndrome: a case report and review of the literature Am I Case Rep. 2018;19:978-84.

9. Micozzi S, Pinto C, Seoane M, et al. Giant cell myocarditis in hypersensitivity reactions: is an early diagnose possible? Ann Allergy Asthma Immunol. 2015;115:247-8

10. Becker $B A$, Caruthers $C N$, Jureidini $S$, et al. Non-invasive management of myocarditis despite a negative gadolinium-enhanced cardiac MRI in a 15-year-old boy with minocycline triggered DRESS syndrome. J Allergy Clin Immuno. 2015;135:AB123.

11. Wu PA, Anadkat MJ. Fever, eosinophilia, and death: a case of minocycline hypersensitivity. Cutis. 2014;93:107-10.

12. Taylor $\mathrm{JL}$, Kulkarni MS, Behringer EC, et al. Minocycline-induced drug reaction with eosinophilia and systemic symptoms drug reaction with eosinophilia and systemic symptoms
syndrome: myocarditis and multiple organ failure. ICU Director. syndrome: myocard

13. Shaughnessy KK, Bouchard SM, Mohr MR, et al. Minocycline-induced drug reaction with eosinophilia and systemic symptoms (DRESS) syndrome with persistent myocarditis. J Am Acad Dermatol. 2010;62:315-8.

14. Lee C-W, Mitchell RN, Horan RF, et al. Cardiogenic shock and peripheral eosinophilia in a young woman. Ann Allergy Asthma Immunol. 2005;95:229-33.

15. Parneix-Spake A, Bastuji-Garin S, Lobut JB, et al. Minocycline as possible cause of severe and protracted hypersensitivity drug reaction. Arch Dermatol. 1995:131:490-1.

16. Ardérius M, Menezes MN, Marques T, et al. Late recurrence of fulminant myocarditis related to HSS/DRESS. Cor Vasa. 2018;60:e635-7.

17. Jeremic I, Vujasinovic-Stupar $\mathrm{N}$, Terzic $\mathrm{T}$, et al. Fatal sulfasalazine-induced eosinophilic myocarditis in a patient with periodic fever syndrome. Med Princ Pract. 2014:24:195-7.

18. Daoulah A, Alqahtani AAR, Ocheltree SR, et al. Acute myocardial infarction in a 56-year-old female patient treated with sulfasalazine. Am J Emerg Med. 2012;30:638.1-638.e3.

19. Lau G, Kwan C, Chong SM. The 3-week sulphasalazine syndrome strikes again. Forensic Sci Int. 2001;122:79-84.

20. Hoogeveen RM, van der Bom T, de Boer HH, et al. A letha case of the dapsone hypersensitivity syndrome involving the myocardium. Neth J Med. 2016;74:89-92.

21. Pereira CM, Vaz M, Kotha S, et al. Dapsone hypersensitivity syndrome with myocarditis. J Assoc Physicians India. 2014:62:728-31.

22. Li W-H, Liu H-N, Lee D-D. Myocarditis in dapsone-induced drug reaction with eosinophilia and systemic symptomscase report and review of the literature. Dermatologica Sinica. 2011;29:63-6.

23. Zhu KJ, He FT, Jin $\mathrm{N}$, et al. Complete atrioventricular block associated with dapsone therapy: a rare complication of dapsone-induced hypersensitivity syndrome. J Clin Pharm Ther. 2009;34:489-92.

24. Lau G. A fatal case of drug-induced multi-organ damage in a patient with Hansen's disease: dapsone syndrome or rifampicin toxicity? Forensic Sci Int. 1995;73:109-15.

25. Thongsri T, Chularojanamontri L, Pichler WJ. Cardiac involvement in DRESS syndrome. Asian Pac J Allergy Immunol. 2017;35:3-10.

26. Teo RYL, Tay Y-K, Tan C-H, et al. Presumed dapsone-induced drug hypersensitivity syndrome causing reversible hypersensitivity myocarditis and thyrotoxicosis. Ann Acad Med Singap. 2006;35:833-6.

27. Hase J, Milgrom B. A case of DRESS myocarditis. Presented at: Hospital Medicine Conference, San Diego, CA, USA 6-9 March 2016.

28. Çetin M, Mis MD, Karaman K, et al. Carbamazepine-induced DRESS syndrome leading to reversible myocarditis in a child. Cent Eur J Immunol. 2019;44:102-5.

29. Kowtoniuk R, Pinninti M, Tyler W, et al. DRESS syndrome-associated acute necrotizing eosinophilic myocarditis with giant cells. BMJ Case Rep. 2018;bcr-2018-226461.

30. Hagiwara H, Fukushima A, Iwano $\mathrm{H}$, et al. Refractory cardiac myocarditis associated with drug rash with eosinophilia and systemic symptoms syndrome due to anti-bipolar disorder drugs: a case report. Eur Heart I Case Rep. 2018;2:yty100.

31. Lau E, Januzzi J. It's all in the differential: new cardiomyopathy in a 52-year-old man with DRESS. J Am Coll Cardiol. 2018;71:A2369

32. Guenther $M$, Sulistio $M$, Khan D. A challenging case of DRESS with myocarditis. Ann Allergy Asthma Immunol. 2018;121:S69.

33. Karagic M, Vos GD. Drug rash with eosinophilia and systemic symptoms (DRESS) SYNDROME hypersensitivity myocarditis presenting with cardiogenic shock. Ann Allergy Asthma Immunol. 2018;121:S82.

34. Menter T, Tzankov A. Drug reaction, eosinophilia, and systemic symptoms (DRESS) syndrome associated with allopurinol leading to acute necrotizing eosinophilic myocarditis and deat due to papillary muscle rupture. J Allergy Clin Immunol Pract. 2016;4:1262-4

35. Zhang S-N, He Q-X, Yang N-B, et al. Isoniazid-induced drug rash with eosinophilia and systemic symptoms (DRESS) syndrome presenting as acute eosinophilic myocarditis. Intern Med. 2015;54:1227-30
36. $\mathrm{Ho} \mathrm{CH}$, Uzunyan MY. Myocarditis in drug rash with eosinophilia and systemic symptoms. Cardiol Young. 2015;25:1210-3.

37. Park Y, Ahn SG, Ko A, et al. Hypersensitivity myocarditis confirmed by cardiac magnetic resonance imaging and endomyocardial biopsy. Korean I Intern Med. 2014:29:236-40.

38. Lee WF, Seow CJ, Jong M. A rare presentation of DRESS-associated thyrotoxicosis and myocarditis: case report. Endocrine Abstracts. 2013;32:P325

39. Eppenberger M, Hack D, Ammann P, et al. Acute eosinophilic myocarditis with dramatic response to steroid therapy: the central role of echocardiography in diagnosis and follow-up. central role of echocardiography

40. Pursnani A. Hypersensitivity myocarditis associated with azithromycin exposure. Ann Intern Med. 2009;150:225

41. Sabatine MS, Poh K-K, Mega JL, et al. Case 36-2007: A 31-year-old woman with rash, fever, and hypotension. N Engl J Med. 2007;357:2167-78.

42. Sekiguchi A, Kashiwagi T, Ishida-Yamamoto A, et al. Drug-induced hypersensitivity syndrome due to mexiletine associated with human herpes virus 6 and cytomegalovirus reactivation. J Dermatol. 2005;32:278-81.

43. Zaidi AN. Anticonvulsant hypersensitivity syndrome leading to reversible myocarditis. Can I Clin Pharmacol. 2005;12:e33-40.

44. Aggarwal A, Bergin $P$, Jessup $P$, et al. Hypersensitivity myocarditis presenting as cardiogenic shock. J Heart Lung Transplant. 2001:20:1241-4.

45. Beghetti M, Wilson GJ, Bohn D, et al. Hypersensitivity myocarditis caused by an allergic reaction to cefaclor. $J$ Pediatr. 1998;132:172-3.

46. Arima M, Kanoh T, Yamasaki A, et al. Eosinophilic myocarditis associated with toxicodermia caused by phenobarbital. Jpn Circ J. 1998;62:132-5.

47. Garty BZ, Offer I, Livni E, et al. Erythema multiforme and hypersensivity myocarditis caused by ampicillin. Ann Pharmacother. 1994;28:730-1.

48. Bourgeois GP, Cafardi JA, Groysman V, et al. Fulminant myocarditis as a late sequela of DRESS: Two cases. J Am Acad Dermatol. 2011:65:889-90.

49. deMello DE, Liapis $H$, Jureidini $S$, et al. Cardiac localization of eosinophil-granule major basic protein in acute necrotizing myocarditis. N Eng/ J Med. 1990;323:1542-5.

50. Herzog CA, Snover DC, Staley NA. Acute necrotising eosinophilic myocarditis. Heart. 1984;52:343-8.

51. Damsky WE, Vesely MD, Lee Al, et al. Drug-induced hypersensitivity syndrome with myocardial involvement treated with tofacitinib. JAAD Case Rep. 2019;5:1018-26

52. Intarasupht J, Kanchanomai A, Leelasattakul W, et al. Prevalence, risk factors, and mortality outcome in the drug reaction with eosinophilia and systemic symptoms patients with cardiac involvement. Int I Dermatol. 2018;57:1187-91

53. Ben m'rad M, Leclerc-Mercier S, Blanche P, et al. Drug-induced hypersensitivity syndrome: clinical and biologic disease patterns in 24 patients. Medicine 2009:88:131-40.

54. Eshki M, Allanore L, Musette $P$, et al. Twelve-year analysis of severe cases of drug reaction with eosinophilia and systemic symptoms: a cause of unpredictable multiorgan failure. Arch Dermatol. 2009;145:67-72. 